\title{
EST analysis of cDNA libraries from the entomopathogenic fungus Beauveria (Cordyceps) bassiana. II. Fungal cells sporulating on chitin and producing oosporein
}

\author{
Eun-Min Cho, ${ }^{1}$ Drion Boucias ${ }^{2}$ and Nemat O. Keyhani ${ }^{1}$ \\ Department of Microbiology and Cell Science ${ }^{1}$ and Department of Entomology and \\ Nematology², University of Florida, Gainesville, FL 32611, USA
}

Correspondence

Nemat O. Keyhani

keyhani@ufl.edu

Received 13 January 2006

Revised 22 May 2006

Accepted 24 May 2006
In the accompanying paper [Cho, E.-M., Liu, L., Farmerie, W. \& Keyhani, N. O. (2006). Microbiology $152,2843-2854]$, the analysis of expressed sequence tag (EST) libraries derived from homogeneous single-cell populations of aerial conidia, in vitro blastospores and submerged conidia of the entomopathogenic fungus Beauveria (Cordyceps) bassiana has been reported. Here an extended EST analysis is presented of complex cell mixtures derived from fungal cells sporulating on chitin or grown under culture conditions inducing the production of the B. bassiana secondary metabolite, oosporein. Fungal material used for the construction of the libraries included germinating conidia and blastospores, mycelia, as well as cells in various developmental stages. Approximately $25005^{\prime}$ end sequences were determined from random sequencing of clones from each library, and were clustered into 277 contigs with 1069 singlets, and 306 contigs with 1064 singlets, for the chitin and oosporein libraries, respectively. Almost half (45-50\%) of the sequences in each library displayed either no significant similarity (e value $>10^{-4}$ ) or similarity to hypothetical proteins found in the $\mathrm{NCBI}$ database. Approximately $20-25 \%$ of the sequences in each library could be annotated by gene ontology terms. A comparative analysis between the two libraries, as well as the libraries in the accompanying paper, is presented. A set of 4360 clustered and unique sequences was characterized. The data are indicative of a highly plastic gene expression repertoire being available to $B$. bassiana for growth during different environmental and developmental conditions, and provides a dataset for gene discovery and genome annotation.

\section{INTRODUCTION}

The entomopathogenic fungus Beauveria bassiana is a globally distributed hyphomycete under intensive study as a biocontrol agent for a variety of pest insects. Displaying a broad host range and being able to target a diverse number of arthropod species (Clarkson \& Charnley, 1996; Ferron, 1981; Gupta et al., 1992; Kucera \& Samsinakova, 1968; Leathers et al., 1993; McCoy, 1990; St Leger et al., 1986), strains of B. bassiana have been selected for control of insects and other arthropods that act as disease vectors, including mosquitoes and ticks (Clark et al., 1968; Kirkland et al., 2004), crops pests such as whiteflies, caterpillars, grasshoppers and borers (Brownbridge et al., 2001; De la Rosa et al., 2000; Khachatourians, 1992; Leathers \& Gupta, 1993;

Abbreviations: EST, expressed sequence tag; GO, gene ontology.

The GenBank/EMBL/DDBJ accession numbers for the EST sequences reported in this paper are shown in the Supplementary Tables.

A figure and tables with further details about the EST data are available as supplementary data with the online version of this paper.
Wraight et al., 1998), and even ecologically hazardous, invading pests such as fire ants and termites (Broome et al., 1976; Culliney \& Grace, 2000). Beauveria sp. have been recognized as important ecological agents in regulating insect populations, and appear to be able to colonize and/or interact within plant rhizospheres as an endophyte (Bing \& Lewis, 1992; Lewis et al., 2001).

Aside from their use in biological control regimes, Beauveria sp. are the second most widely used whole-cell eukaryotic biocatalysts, and are responsible for a range of biological transformations and remediations that remain elusive via chemical and synthetic methods (Grogan \& Holland, 2000). Beauveria sp. produce an array of secondary metabolites, including oosporein, a red dibenzoquinone, which can oxidize proteins and amino acids (El Basyouni \& Vining, 1966; Kucera \& Samsinakova, 1968; Seger et al., 2005). Oosporein displays antibiotic activity towards Gram-positive (but not Gram-negative) bacteria, and appears to cause avian gout in chickens and turkeys (Pegram et al., 1982). Other important metabolites produced by Beauveria sp. include bassianin and tenellin, yellow pigments that affect membrane 
ATPases, various antimicrobial hexadepsipeptides known as beauvericins, as well as small molecular mass organic compounds, such as oxalic acid, that play important roles in pathogenesis (Isaka et al., 2005; Jeffs \& Khachatourians, 1997; Kagamizono et al., 1995; Kirkland et al., 2005; Takahashi et al., 1998).

Despite this interest, the molecular mechanisms of entomopathogenicity, endophyte establishment or rhizosphere competence, and B. bassiana-mediated biochemical transformations, are largely unknown. Few of the genes encoding proteins involved in any of these processes have been described, leaving a wealth of potential for the characterization of novel natural products derived from this organism. Analysis of expressed sequence tag (EST) transcripts expressed during discrete developmental and growth conditions represents an efficient means of characterizing the genome potential of an organism. Large numbers of genes can be rapidly examined in systems where little or no genetic information is available, and this information can be used to develop models regarding virulence factors and pathways important for the insect-fungus association, as well as give insights into biochemical pathways that lead to the many interesting metabolites produced by $B$. bassiana. In the accompanying paper (Cho et al., 2006), we analysed ESTs derived from homogeneous distinct single cell populations derived from B. bassiana, namely, aerial conidia, in vitro blastospores and submerged conidia. In an effort to maximize the diversity of transcripts isolated, two additional cDNA libraries were constructed from fungi sporulating on chitin, the major carbohydrate constituent of arthropod cuticles, and from cultures grown under conditions that lead to the production of oosporein. An overall comparative analysis between all five libraries is discussed.

\section{METHODS}

Cultivation of fungi. B. bassiana (ATCC 90517) was routinely grown on potato dextrose agar (PDA). Plates were incubated at $26^{\circ} \mathrm{C}$ for $10-14$ days and aerial conidia were harvested by flooding the plate with sterile $\mathrm{dH}_{2} \mathrm{O}$. Conidial suspensions were filtered through a single layer of Miracloth and final spore concentrations were determined by direct count using a haemocytometer. For the chitin library, conidia $\left(2 \times 10^{5}\right.$ cells $\mathrm{ml}^{-1}$ final concentration) were inoculated into $500 \mathrm{ml}$ Sabouraud dextrose broth/1\% chitin (Sigma-Aldrich) and grown for 18 days at $25^{\circ} \mathrm{C}$ with aeration (shaking incubator, 150 r.p.m.). Oosporein (Oos) medium (per litre: $50 \mathrm{~g}$ glycerol, $2 \mathrm{~g} \mathrm{NaNO}_{3}, 1 \mathrm{~g} \mathrm{KH}_{2} \mathrm{PO}_{4}, 0.5 \mathrm{~g} \mathrm{KCl}, 0.5 \mathrm{~g} \mathrm{MgSO}_{4} .7 \mathrm{H}_{2} \mathrm{O}$, $0.02 \mathrm{~g} \mathrm{FeSO}_{4} .7 \mathrm{H}_{2} \mathrm{O}$ ) was used for the induction of oosporein production in B. bassiana (El Basyouni \& Vining, 1966). Conidia (1 ml, $1 \times 10^{8}$ cells $\mathrm{ml}^{-1}$ ) were inoculated into $500 \mathrm{ml}$ Oos media and grown for 10 days at $25^{\circ} \mathrm{C}$ with aeration. For each culture, the total fungal cell mass was harvested by centrifugation and washed once with sterile $\mathrm{dH}_{2} \mathrm{O}$, after which $1 \mathrm{ml}$ RNAlater (Ambion) was allowed to penetrate into the pellet. After $10 \mathrm{~min}$, the sample was quick frozen in liquid nitrogen, the cell pellet lyophilized, and the resultant powder stored at $-80^{\circ} \mathrm{C}$ until use.

Construction, characterization and sequencing of the cDNA libraries. RNA isolation, construction of the cDNA libraries in the unidirectional pBluescript II XR system (Stratagene), and subsequent plasmid isolation and DNA sequencing were performed as previously described (Cho et al., 2006). Approximately 2500 clones were picked at random from each library and subjected to single pass $5^{\prime}$ end sequencing. The mean insert size of the cDNA libraries was 1.1 and $0.85 \mathrm{~kb}$ for the oosporein and chitin libraries, respectively, with an overall range of between $0 \cdot 3$ and $3 \cdot 0 \mathrm{~kb}$. After editing the mean length of the single read sequences ranged from $0 \cdot 4$ to $0 \cdot 5 \mathrm{~kb}$.

Sequence analysis. EST sequence clustering, assembly and gene ontology (GO) mappings were performed as described previously (Cho et al., 2006).

\section{RESULTS AND DISCUSSION}

\section{Characterization of the EST database}

EST libraries were constructed from mRNA derived from $B$. bassiana grown on chitin or under conditions that induced expression of the fungal secondary metabolite oosporein. Harvested cultures were heterogeneous, and contained extensive hyphal growth and mycelia, and conidia and/or blastospores in various developmental stages. The oosporein culture supernatant was bright pink/red before harvest, indicating the production and secretion of oosporein. An analysis of the total number of valid ESTs, the assembly of the ESTs into groups of cDNAs that share sequence identity and were considered to represent transcripts of the same gene (contigs), the number of singlets, and the diversity index for each library are given in Table 1 . The representative nature of the libraries was confirmed by the high degree of transcript diversity. The number of sequences clustering into contig groups was noticeably different between the oosporein and chitin libraries at the higher end of the distribution, with the former containing no sequences represented more than 20 times, whereas the latter contained four contigs represented by 22, 24, 37 and 65 ESTs (Fig. 1).

\section{Functional analysis of the EST libraries}

The unigene sets for each library were used for similarity searches. BLASTX searches using $E$ values of $\leqslant 10^{-4}$ identified contigs with amino acid sequence similarity to previously characterized proteins deposited in the

Table 1. Summary of $B$. bassiana EST sequencing data

\begin{tabular}{|lcr|}
\hline & Oosporein & Chitin \\
\hline Total no. of runs & 2547 & 2495 \\
Total no. of valid ESTs & 2030 & 2134 \\
Total no. of contigs & 306 & 277 \\
No. of ESTs in contigs & 966 & 1065 \\
Total no. of singlets & 1064 & 1069 \\
Total no. of unique sequences & 1370 & 1346 \\
Diversity index $(\%)$ & 68 & 63 \\
\hline
\end{tabular}

${ }^{\star}$ Diversity index $=$ total no. of unique sequences/total no. of valid ESTs. 


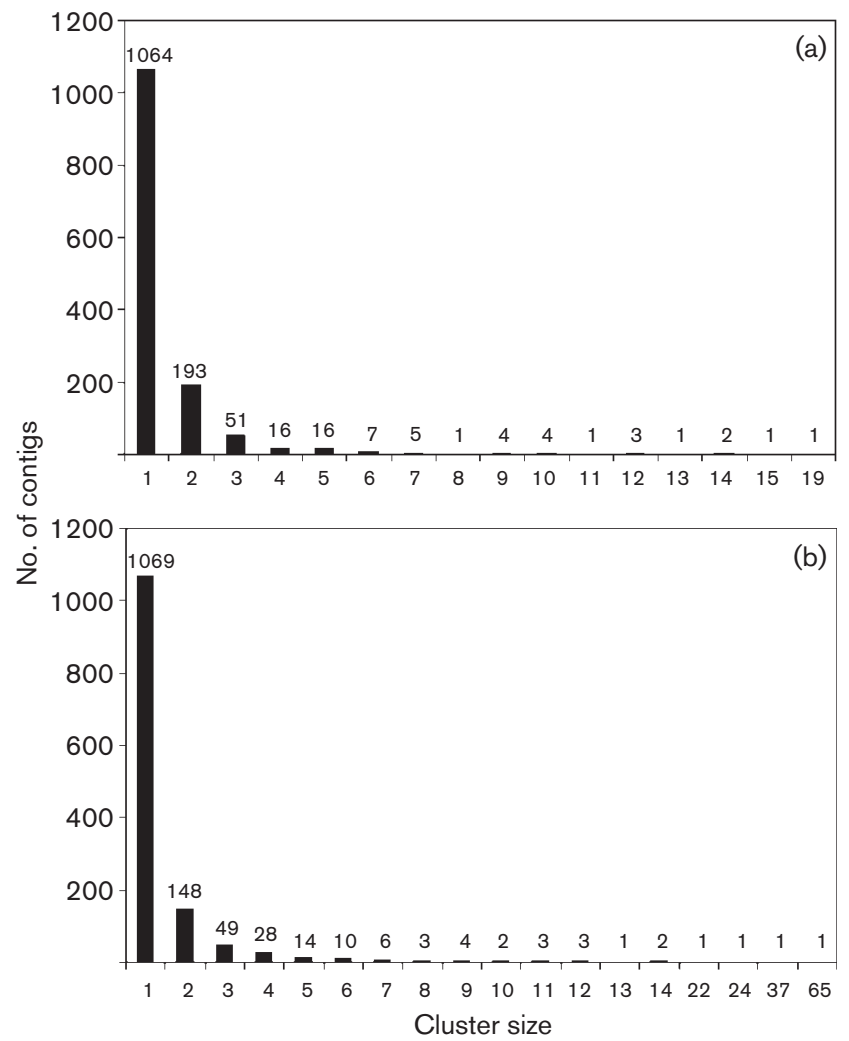

Fig. 1. EST redundancy in contig assembly: (a) oosporein and (b) chitin.

GenBank non-redundant and/or Swissprot databases (as of September 2005) and were used to extract gene annotation terms for grouping sequences into functional classifications. The complete search results and GenBank submission numbers for each EST are available as supplementary data with the online journal (Supplementary Table S1).

Annotation and analyses were performed using all valid ESTs (in total 2030 and 2134 from the oosporein- and chitin-derived libraries, respectively) and on the best redundant ESTs from the contigs (1370 and 1346 from the oosporein- and chitin-derived libraries, respectively). Similarity matches $\left(e\right.$ value $<10^{-4}$ ) to proteins in the GenBank/Swissprot databases were identified for 648 out of 1346 ESTs (48\%) and 566 out of 1370 ESTs (41\%) for the chitin and oosporein libraries, respectively. Approximately $75-85 \%$ of sequences displaying matches were mapped to GO categories. Most hits were detected among ascomycete sequences $(70-80 \%)$, with only $2 \%$ of the hits detected among the basidiomycete sequences. Approximately $10 \%$ of the sequences were most similar to sequences from animals or prokaryotes, with a smaller set showing similarity to plant, archaeal or protist sequences.

ESTs derived from the unigene set with BLASTX $e$ values $<10^{-4}$ were parsed into one or more subcategories within the biological processes (containing 12 major subcategories), cellular components (containing 8 subcategories), and molecular functions (containing 12 subcategories) hierarchies of GO representations (Farmerie et al., 2005; Harris et al., 2004). The distribution of ESTs within each subcategory is presented for the oosporein (Fig. 2) and the chitin (Fig. 3) libraries. A table of these results is available as supplementary data with the online journal (Supplementary Table S2).

\section{Analysis of the oosporein and chitin EST libraries}

Approximately $17 \%$ of the ESTs in each of the oosporein and chitin libraries were unique and not found in any of the other libraries, including those presented in the accompanying paper (Cho et al., 2006). In a number of cases, clones that did not cluster displayed similarity search hits to the same protein. For example, two different oosporein contigs (oosporein.113.c1 and oosporein.266.c1, comprised of two sequences each), were similar ( $e$ values $3 \cdot 2 \times 10^{-35}$ and $7 \cdot 43 \times 10^{-12}$, respectively) to the Saccharomyces cerevisiae spore wall maturation protein DIT1 involved in the production of dityrosine containing macromolecules in the spore wall. These contigs could not be aligned into a larger contig, although a partial overlap (less than $40 \%$ identity) could be noted over an approximately $100 \mathrm{bp}$ region; however, the level of mismatch would indicate that these are indeed distinct transcripts.

Broad functional categorization of the ESTs isolated from the oosporein and chitin libraries revealed similar expression representation of catabolic pathways, carbohydrate metabolism and other metabolism categories, including protein, nucleic acid and amino acid catabolism, and biosynthesis. A twofold difference in the representation of phosphorus metabolism ESTs was noted in the oosporein as compared to the chitin library (see Supplementary Fig. S1 available with the online journal). The distribution of sequences within ribosomal and mitochondrial intracellular categories was similar between the two libraries, although some variation in cytoskeletal, nuclear and membrane subcategories could be seen. The oosporein library contained a slightly greater proportion of transferases (12\%, versus $9 \%$ for the chitin library), with both libraries displaying very similar patterns of representation with respect to hydrolases, oxidoreductases, lyases, ligases and isomerases. Helicase transcripts were identified in the oosporein but not in the chitin library. Little variation was observed in the annotated sequences sorted by ligand-binding categories between the two libraries.

The top two most abundant ESTs found in both the oosporein and chitin libraries did not display any significant hits to any sequences currently in the databases (Table 2, see Supplementary Table S3 available with the online journal, for the 25 most represented transcripts). Indeed, 13 of the top 25 most abundant ESTs found in the chitin library, representing approximately $10 \%$ of the total transcripts sequenced, displayed no significant hits to sequences in the 
(a) Biological processes

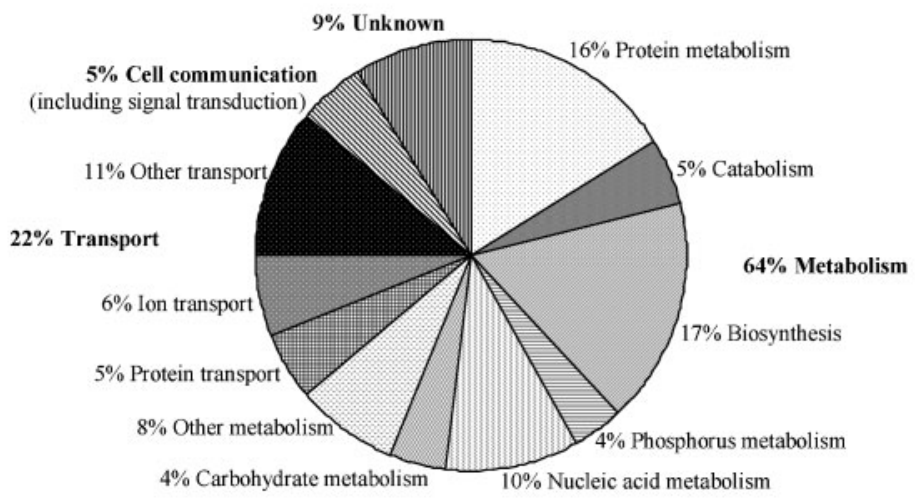

(b) Cellular components
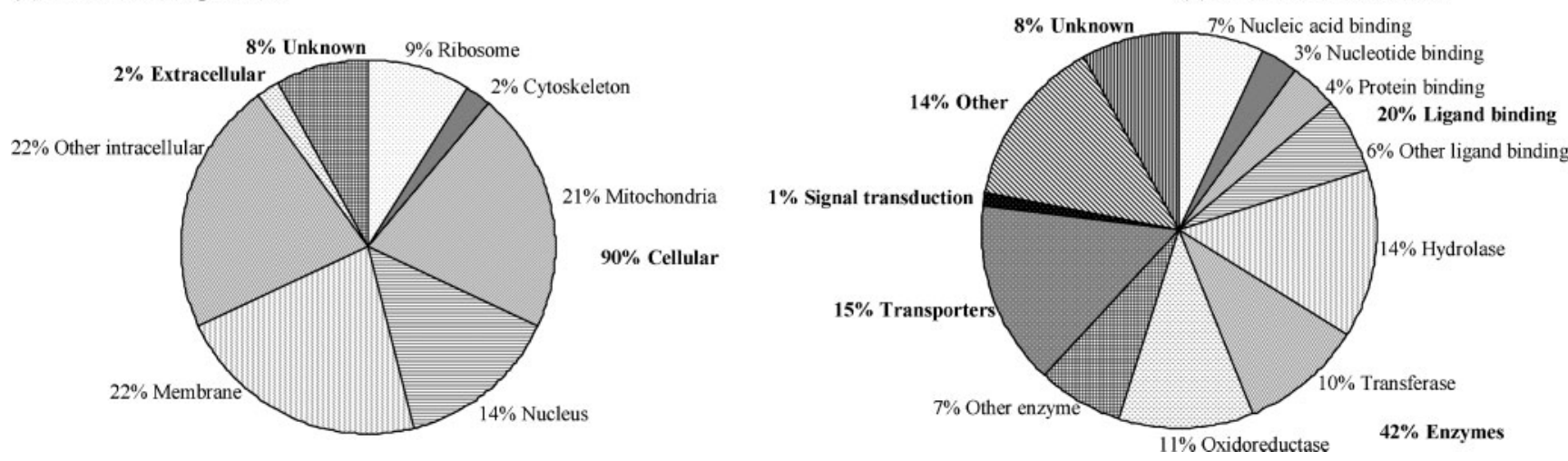

Fig. 2. Percentage representation of GO mappings for $B$. bassiana ESTs derived from the oosporein cDNA library.

databases. In contrast, only 9 of the top 25, representing less than $5 \%$ of the total dataset in the oosporein library, had no significant hits. Abundant ESTs shared between the two libraries included elongation factor $1-\alpha$, histone $\mathrm{H} 3$, an ATP synthase component, ADP/ATP translocase, transaldolase, a putative clock-controlled protein, a hydrophobin (see the accompanying paper, Cho et al., 2006) and a number of ESTs with no significant hits in the searched databases (e.g. oosporein.033.c1 and chitin.032.c1).

Amongst unique ESTs, the oosporein library contained transcripts similar to three different chitin synthases likely to be involved in cell wall biogenesis (Roncero, 2002; RuizHerrera et al., 2002), including ESTs (for a list of the ESTs discussed, with accession numbers and search results, see Supplementary Table S4 available with the online journal) similar the Neurospora crassa class III chitin synthases $3, \mathrm{~N}$. crassa chitin synthase 4 (class IV), and a second putative class IV gene similar to Ustilago maydis chitin synthase 6. The oosporein EST collection contained a diverse number of nutrient uptake systems, including ESTs similar to a $S$. cerevisiae dicarboxylic amino acid transporter (Regenberg et al., 1999), a Trichoderma harzianum broad-range amino acid permease induced during growth on Rhizoctonia solani cell walls (Vasseur et al., 1995), a Candida albicans peptide transporter (Basrai et al., 1995), an Aspergillus nidulans high-affinity proline-specific permease (Sophianopoulou \& Scazzocchio, 1989) and an S. cerevisiae $\alpha$-glucoside (maltose) and lactose permeases (Chang \& Dickson, 1988; Han et al., 1995).

The oosporein library also contained a range of hydrolases, including proteases, phosphatases, lipases and nucleases, but in contrast to the chitin library, no chitinases. A number of different ESTs were similar to a class of unique proteases relatively insensitive to specific inhibitors of ordinary acid or aspartic proteinases, such as pepstatin, and other compounds. In one instance, two different oosporein EST contigs were similar to the same protein, namely, the Aspergillus niger var. macrosporus endopeptidase or aspergillopepsin (Inoue et al., 1991). One such contig (oosporein.167.C1, e value $<10^{-100}$ ) was represented moderately (seven times), whereas the other (oosporein.240.C1, $e$ value $=3 \cdot 25 \times 10^{-39}$ ) comprised two sequences. Although the sequences of these two contigs could not be aligned into a single contig and have been scored as representing separate transcripts (and hence genes), they were approximately $80 \%$ identical. A third EST was similar to the skin disease-causing dermatiaceous coelomycete Scytalidium dimidiatum (lignocolum) scytalidopepsin B, which also belongs to the pepstatin-insensitive acid protease family (Oda et al., 1998). In addition, the 
(a) Biological processes

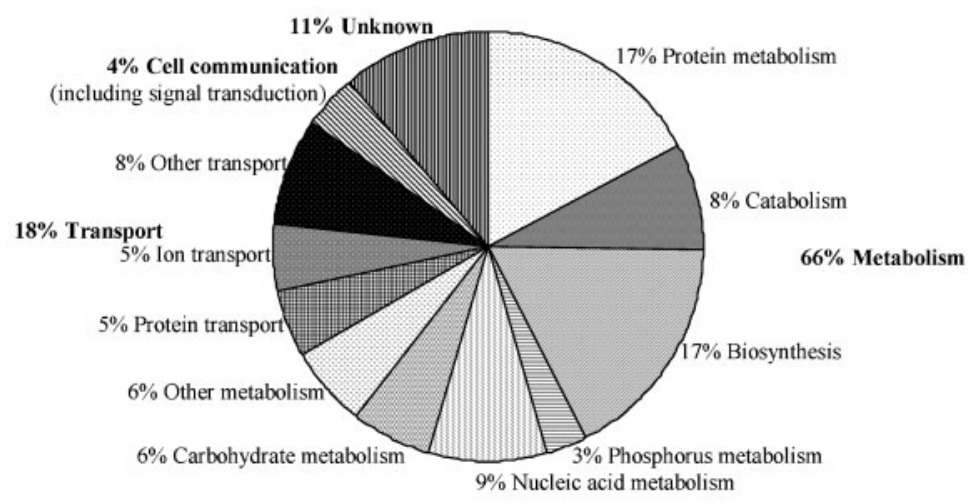

(b) Cellular components

(c) Molecular functions
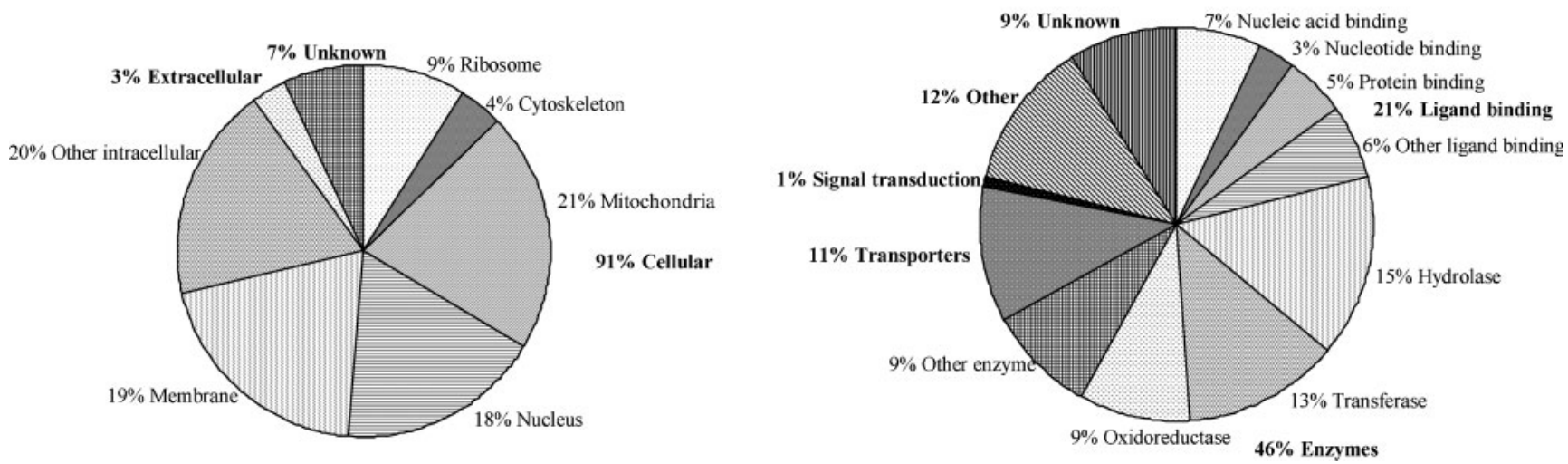

Fig. 3. Percentage representation of GO mappings for $B$. bassiana ESTs derived from the chitin cDNA library.

oosporein collection contained an EST with similarity to an $S$. cerevisiae prenylmetalloprotease required for proper processing and secretion of yeast mating factors (FujimuraKamada et al., 1997). Other hydrolases included ESTs similar to carboxypeptidase, two tripeptidyl peptidases (which could not be aligned into a single EST contig), acid phosphatase, endonuclease and cellobiase.

Although the production of toxic metabolites by $B$. bassiana is well known, to date, none of the genes that encode enzymes involved in the biosynthesis of these compounds has been reported. The synthesis of enniatins and cyclosporins, both $N$-methylated cyclohexadepsipeptides produced by Fusarium and Beauveria species (Kamyar et al., 2004; Lawen, 1996), are catalysed by large single polypeptide multifunctional enzymes that belong to the class of nonribosomal peptide synthases (Glinski et al., 2002; Haese et al., 1993; Herrmann et al., 1996). We have identified ESTs in both the oosporein and chitin libraries similar to the Fusarium enniatin synthetase (oosporein_10H08.e, $e$ value $=7 \cdot 6 \times 10^{-7}$, chitin_8-D06.e, $e$ value $=$ $\left.4 \times 10^{-42}\right)$. These two ESTs did not contain any overlapping sequences (and hence did not cluster into a contig) but in this case due to the length of the ennitain gene $(\sim 10 \mathrm{~kb})$ they could represent different regions of the same transcript.
In addition to the production of toxic metabolites, entomopathogenic fungi are able to persist within the insect haemolymph as freely circulating hyphal bodies where they interface with the host innate immune responses (Pendland et al., 1993). These reactions rely upon recognition and targeting of foreign cells, and successful pathogens have developed a range of mechanisms for masking their presence, mostly involving alterations in cell wall composition. This can involve modifications of cell-surface carbohydrates and/or proteins (Brown \& Gordon, 2005; Gillespie et al., 2000; Pendland \& Boucias, 1998). Mucins form a protective coat surrounding many epithelial cells, and are very hydrophilic glycoproteins that provide a scaffold for the attachment of oligosaccharides (Gum et al., 1994). Interestingly, the oosporein library contained an EST (oosporein_24-C12.e, $e$ value $=4 \cdot 4 \times 10^{-7}$ ) similar to human mucin 2 (Gum et al., 1994).

The cDNA library derived from chitin-grown cells contained a number of unique ESTs, including three chitinases: two similar to the Coccidioides immitis complement-fixation antigen endochitinase (Zimmermann et al., 1996) (again these sequences could not be aligned into a single contig, but may still represent transcripts of the same gene), and another similar to C. albicans chitinase 3 (McCreath et al., 1995). A number of other glycosidases were found including 
Table 2. The most abundantly represented transcripts in the $B$. bassiana oosporein and chitin libraries

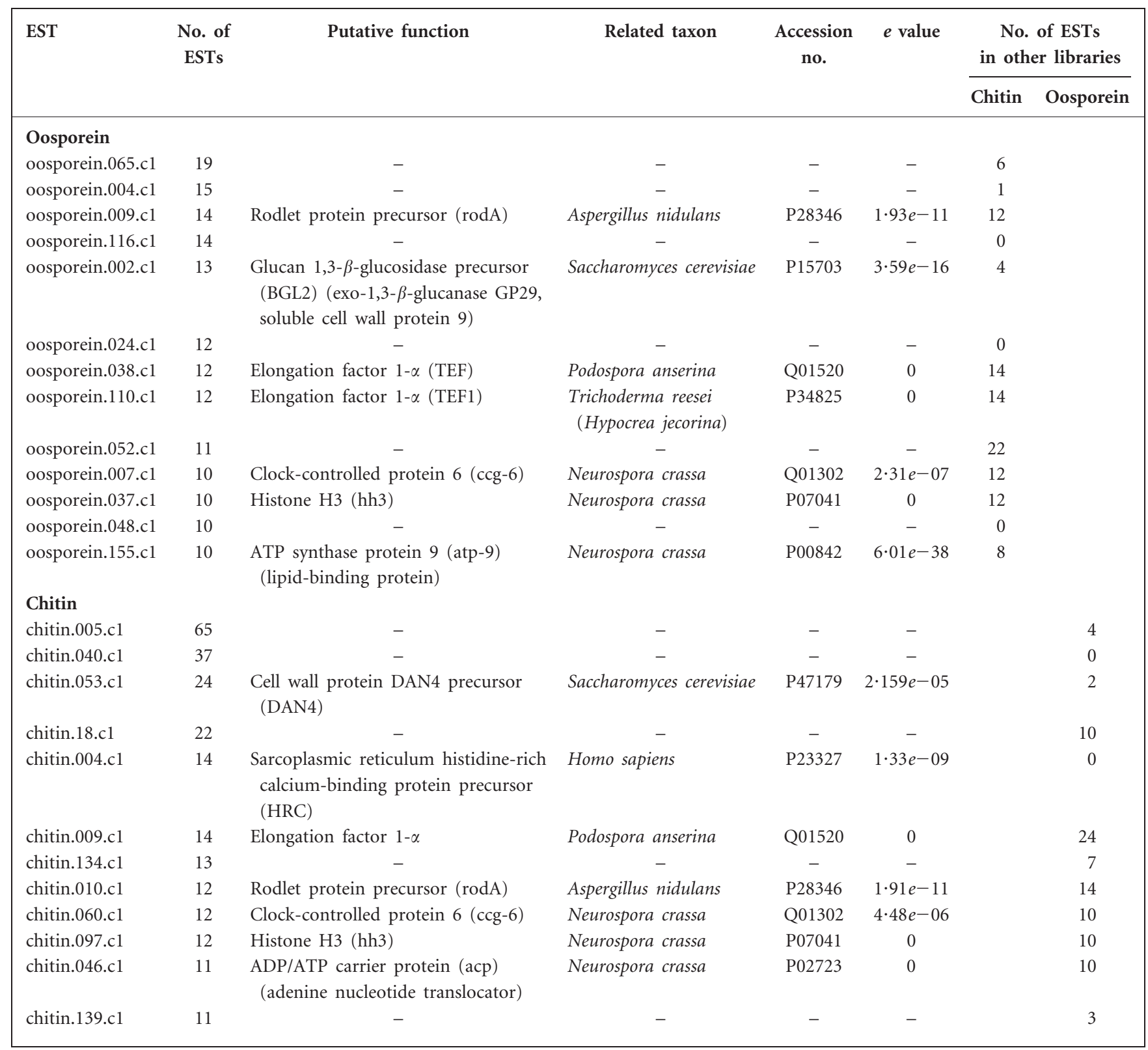

- , No significant search results for query $\left(e\right.$ value $\left.>10^{-3}\right)$.

a melibiase, and two ESTs similar to $1,3-\beta$-glucanases most likely involved in cell wall remodelling.

\section{Comparative analysis between the aerial conidia, in vitro blastospore, submerged conidia, oosporein and chitin libraries}

Subtilisin proteases and other pathogenicity factors. Characterization of EST libraries from aerial conidia, in vitro blastospores and submerged conidia are presented in the accompanying paper (Cho et al., 2006). Along with the EST libraries presented in this report, approximately 4360 different transcripts were identified between the five libraries. Subtilisins represent an important class of pathogenicity factors extensively studied within the context of fungal-mediated insect pathogenesis (Bagga et al., 2004). In this regard, one of the best-studied model systems is the entomopathogenic fungus Metarhizium anisopliae (Bagga et al., 2004; Freimoser et al., 2003a, 2005; Wang \& St Leger, 2005; Wang et al., 2005). Indeed, in M. anisopliae overexpression of a subtilisin has been demonstrated to lead to enhanced virulence (St Leger et al., 1996); therefore, a comparative analysis between the $B$. bassiana and M. anisopliae subtilisins was performed (Table 3). Depending upon the strain, $M$. anisopliae can produce up to 11 different subtilisins, many of which are upregulated 
during growth on insect cuticle. These enzymes have been grouped into four groups: class I ('bacterial') subtilisin (Pr1C), and three groups of proteinase K-like class II subtilisins, extracellular subfamily 1 ( $\operatorname{Pr} 1 \mathrm{~A}, \operatorname{Pr} 1 \mathrm{~B}, \operatorname{Pr} 1 \mathrm{G}, \operatorname{Pr} 1 \mathrm{I}$ and $\operatorname{Pr} 1 \mathrm{~K})$, extracellular subfamily 2 (Pr1D, Pr1E, Pr1F and $\operatorname{Pr} 1 \mathrm{~J})$ and an endocellular subtilisin (Pr1H) (Bagga et al., 2004). Our B. bassiana EST collection contained eight different subtilisins displaying various levels of similarity to the M. anisopliae enzymes (Table 3). The aerial conidia library contained seven of these enzymes, four of which were not found in the other EST sets (conidia_11-D01.e, conidia_22-C04.e, conidia_08-G10.e and conidia_12H11.e, see Table 3). The chitin-grown library also contained an enzyme not found in any of the other libraries (chitin_8-G09.e). It should be noted that these sequences represent only a part of the gene; therefore, any conclusions should be taken with some caution. Two of the B. bassiana subtilisins (each represented by two contigs, conidia_22-B05.e/oosporein_9-D06.e and conidia.60.C1/ chitin_24-D01.e) were most similar to the class II extracellular subfamily 1 enzymes $(\operatorname{Pr} 1 \mathrm{~A} / \mathrm{B} / \mathrm{G} / \mathrm{I} / \mathrm{K})$ of $M$. anisopliae [note that it was overexpression of Pr1A that led to enhanced virulence in M. anisopliae (St Leger et al., 1996)]. A distinct B. bassiana class I subtilisin was also noted, and the other three enzymes appeared to represent class II endocellular proteins.

Aside from the subtilisins a wide range of potential virulence and/or pathogenicity factors were also found in the EST collection. Amongst these a variety of hydrolases, including chitinases, esterases, peptidases, phosphatases, phospholipases and proteases (see Supplementary Table S5 available with the online journal), were identified. In addition, a series of proteins involved in the production of toxic secondary metabolites, including the previously mentioned enniatin synthases, as well as several genes whose protein products appear to be involved in sterigmatocystin production, were noted. EST datasets for the entomopathogenic fungi M. anisopliae (ascomycete) and Conidiobolus coronatus (zygomycete) revealed a plethora of secreted hydrolases in the former case, and comparatively few hydrolases (e.g. no phospholipases), antimicrobial compounds, toxic metabolites, and no ESTs with putative roles in antibiotic production in the latter case (Freimoser et al., 2003a, b). Our

Table 3. Comparative analysis of subtilisins in the B. bassiana libraries and in $M$. anisopliae

\begin{tabular}{|c|c|c|c|c|c|c|c|c|c|}
\hline B. bassiana $\mathrm{EST}^{\star}$ & \multicolumn{9}{|c|}{ M. anisopliae proteases $\dagger$} \\
\hline \multicolumn{10}{|l|}{ Submerged conidia } \\
\hline TKI_17-A06.e $\ddagger$ & $5 \cdot 00 e-26$ & $3 \cdot 00 e-09$ & & $4 \cdot 00 e-10$ & $4 \cdot 00 e-12$ & $4 \cdot 00 e-61$ & $6 \cdot 00 e-21$ & & $6 \cdot 00 e-18$ \\
\hline \multicolumn{10}{|l|}{ Aerial conidia } \\
\hline conidia_11-D01.e\$ & $1 \cdot 00 e-05$ & $3 \cdot 00 e-05$ & & $1 \cdot 00 e-16$ & $3 \cdot 00 e-07$ & $4 \cdot 00 e-48$ & $3 \cdot 00 e-06$ & $1 \cdot 00 e-11$ & \\
\hline conidia_22-C04.e & & & $1 \cdot 00 e-51$ & & & & $3 \cdot 00 e-04$ & & $3 \cdot 00 e-04$ \\
\hline conidia_08-G10.e\# & $0 \cdot 05$ & & & & & $8 \cdot 00 e-11$ & & $0 \cdot 021$ & \\
\hline conidia_12-H11.e $\mathrm{e}^{* *}$ & & $0 \cdot 041$ & & & & & & & \\
\hline conidia.60.C1†† & $1 \cdot 00 e^{-123}$ & $1 \cdot 00 e-84$ & $0 \cdot 008$ & $8 \cdot 00 e-49$ & $2 \cdot 00 e-79$ & $2 \cdot 00 e-61$ & $1 \cdot 00 e-116$ & $5 \cdot 00 e-41$ & $7 \cdot 00 e-94$ \\
\hline \multicolumn{10}{|l|}{ Oosporein } \\
\hline chitin.232.C1 $\ddagger$ & & & & & & $6 \cdot 00 e-06$ & & & \\
\hline chitin_24-D01.e $\dagger \dagger$ & $5 \cdot 00 e-79$ & $3 \cdot 00 e-65$ & $0 \cdot 023$ & $7 \cdot 00 e-31$ & $2 \cdot 00 e-44$ & $2 \cdot 00 e-41$ & $2 \cdot 00 e-79$ & $7 \cdot 00 e-33$ & $7 \cdot 00 e-67$ \\
\hline chitin_8-G09.eł‡ & & & & & & $1 \cdot 00 e-07$ & & & \\
\hline
\end{tabular}

${ }^{\star}$ Our analyses indicate eight unique B. bassiana proteases, the ESTs denoted $\neq-\ddagger \neq$, represent singlets or cluster into contigs.

$\dagger \operatorname{Pr} 1 \mathrm{~A}, \operatorname{Pr} 1 \mathrm{~B}, \operatorname{Pr} 1 \mathrm{G}, \operatorname{Pr} 1 \mathrm{I}$ and Pr1K, class II subtilisins, extracellular subfamily 1; Pr1C, class I (bacterial) subtilisin; Pr1D, Pr1E, Pr1F and Pr1J, extracellular subfamily 2; $\operatorname{Pr} 1 \mathrm{H}$, endocellular subtilisin.

¥TKI_17.A06.e, conidia.239.C1, oosporein.63.C1, chitin.232.C1.

§conidia_11-D01.e.

Ilconidia_22-B05.e, oosporein_9-D06.e.

Sconidia_22-C04.e.

\#conidia_08-G10.e.

${ }^{* *}$ conidia_12-H11.e.

$\dagger \dagger$ conidia.60.C1, chitin_24-D01.e.

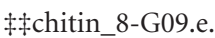




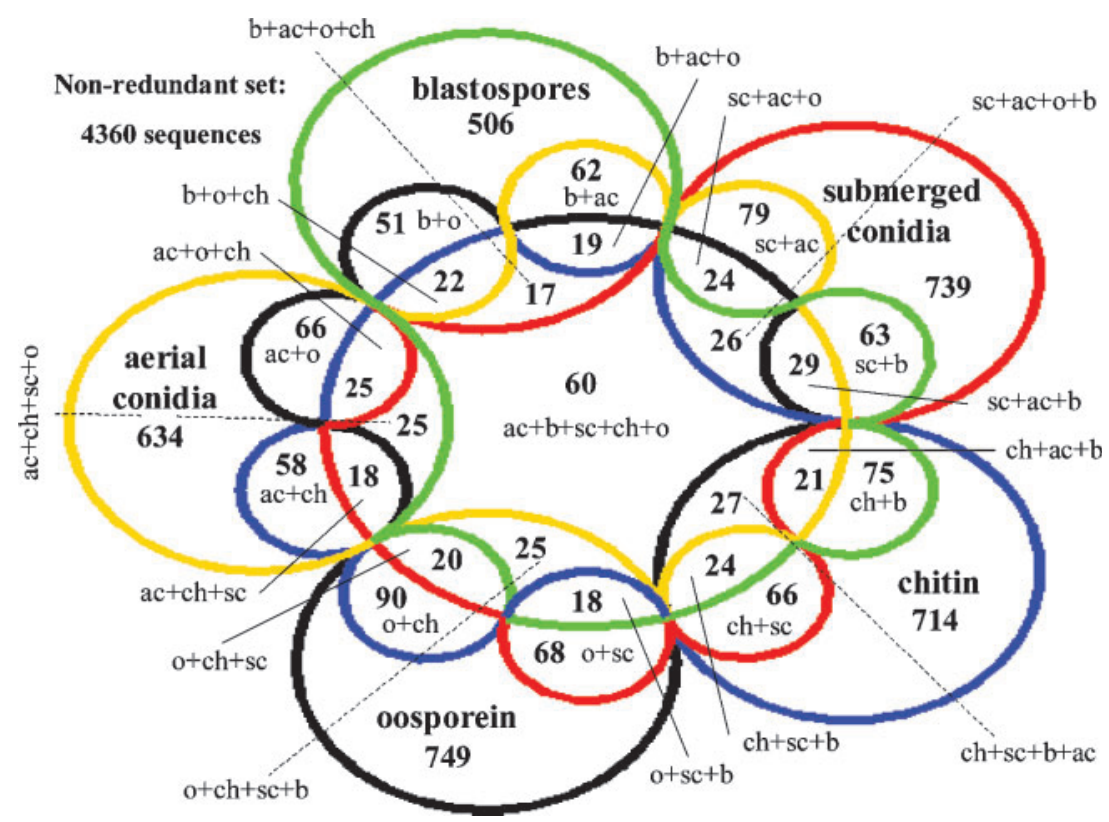

Fig. 4. Comparative analysis of sequenced ESTs derived from the five $B$. bassiana cDNA libraries. The non-simple Venn diagram shows unique and overlapping sets of transcripts between the libraries. The boundaries of each library are delimited by specific colours: ac, aerial conidia (yellow); b, blastospores (green); sc, submerged conidia (red); o, oosporein (black); ch, chitin (blue). results indicate that the adaptations to entomopathogenicity in B. bassiana are closer to those of M. anisopliae in that a wide variety of hydrolases and toxic metabolites, including potential antibiotics, are produced by the fungus.

Shared and unique sequences. An overall analysis of unique and shared sequences between all five libraries was performed and is presented in a non-simple Venn diagram (Fig. 4). A table containing (1) the number of times each sequence was found in each library and (2) the identities of the sequences belonging to each set delineated in Fig. 4 is available as supplementary data with the online journal (Supplementary Table S6). In the figure, the dataset derived from each library is bound by a colour coded line. The outermost ring represents those sequences unique to each library, the second ring sequences uniquely shared between two libraries, the third ring sequences unique to any given three libraries, the fourth ring sequences unique to any four libraries, and the innermost ring ESTs found in all five libraries. To find the full complement of shared sequences several levels need to added, e.g. the unique set of shared sequences between aerial conidia and the oosporein library $(\mathrm{ac}+\mathrm{o})$ is $66 \mathrm{ESTs}$; however, the total shared sequences would include $(\mathrm{ac}+\mathrm{o}=66)+(\mathrm{ac}+\mathrm{o}+\mathrm{ch}=25)+(\mathrm{b}+\mathrm{ac}+\mathrm{o}=19)+(\mathrm{sc}$ $+\mathrm{ac}+\mathrm{o}=24)+(\mathrm{ac}+\mathrm{ch}+\mathrm{sc}+\mathrm{o}=25)+(\mathrm{b}+\mathrm{ac}+\mathrm{o}+\mathrm{ch}=$ 17) $+(\mathrm{sc}+\mathrm{ac}+\mathrm{o}+\mathrm{b}=26)+(\mathrm{ac}+\mathrm{b}+\mathrm{sc}+\mathrm{ch}+\mathrm{o}=60)=$ $66+25+19+24+25+17+26+60=262$ ESTs. An interesting insight gained from the Venn diagram analysis was the high degree of unique sequences present in each library. These results indicate the robust nature of the cDNA libraries and suggest that production of cDNA libraries from distinct developmental conditions can maximize gene diversity in EST data collection. No distinct patterns of gene expression could be surmised from the sorted gene datasets, although the small number of transcripts $(<2 \%)$ shared by all libraries suggest that further sequencing of the libraries is likely to yield additional new transcripts (until this number grows large enough to be considered saturated).

The overall B. bassiana EST collection should provide a means by which gene expression can be measured during development and pathogenesis of this fungus. The range and variety of ESTs corresponding to hydrolases and secondary metabolite products may be indicative of the genomic potential behind the broad host-range capabilities of $B$. bassiana, its growth and development in non-insect habitats (i.e. as saprobes in soil and possibly as endophytes in plants), as well as its ability to rapidly adapt (resulting in increased virulence) to specific targets after passage. The B. bassiana genome consists of 7-8 chromosomes and is estimated at 34-44 Mb (Pfeifer \& Khachatourians, 1993; Viaud et al., 1996). The combined EST dataset will provide a basis for genome annotation and genetic explorations of the molecular basis for the lifestyle adaptations of B. bassiana.

\section{ACKNOWLEDGEMENTS}

The authors wish to acknowledge the assistance of Nashley Harrington, O'Neil Shand and Brett Kirkland for help with the data analysis. This work was supported in part by funds made available from the University of Florida, IFAS and NSF research grant \# EF-0412137.

\section{REFERENCES}

Bagga, S., Hu, G., Screen, S. E. \& St Leger, R. J. (2004). Reconstructing the diversification of subtilisins in the pathogenic fungus Metarhizium anisopliae. Gene 324, 159-169. 
Basrai, M. A., Lubkowitz, M. A., Perry, J. R., Miller, D., Krainer, E., Naider, F. \& Becker, J. M. (1995). Cloning of a Candida albicans peptide transport gene. Microbiology 141, 1147-1156.

Bing, L. A. \& Lewis, L. C. (1992). Endophytic Beauveria bassiana (Balsamo) Vuillemin in corn: the influence of the plant growth stage and Ostrinia nubilalis (Hubner). Biocontrol Sci Technol 2, 39-47.

Broome, J. R., Sikorowski, P. P. \& Norment, B. R. (1976). A mechanism of pathogenicity of Beauveria bassiana on larvae of the imported fire ant, Solenopsis richteri. J Invertebr Pathol 28, 87-91.

Brown, G. D. \& Gordon, S. (2005). Immune recognition of fungal $\beta$ glucans. Cell Microbiol 7, 471-479.

Brownbridge, M., Costa, S. \& Jaronski, S. T. (2001). Effects of in vitro passage of Beauveria bassiana on virulence to Bemisia argentifolii. J Invertebr Pathol 77, 280-283.

Chang, Y. D. \& Dickson, R. C. (1988). Primary structure of the lactose permease gene from the yeast Kluyveromyces lactis. Presence of an unusual transcript structure. J Biol Chem 263, 16696-16703.

Cho, E.-M., Liu, L., Farmerie, W. \& Keyhani, N. O. (2006). EST analysis of cDNA libraries from the entomopathogenic fungus Beauveria (Cordyceps) bassiana. I. Evidence for stage-specific gene expression in aerial conidia, in vitro blastospores and submerged conidia. Microbiology 152, 2843-2854.

Clark, T. B., Kellen, W. R., Fukuda, T. \& Lindegren, J. E. (1968). Field and laboratory studies on the pathogenicity of the fungus Beauveria bassiana to three genera of mosquitoes. J Invertebr Pathol $11,1-7$.

Clarkson, J. M. \& Charnley, A. K. (1996). New insights into the mechanisms of fungal pathogenesis in insects. Trends Microbiol 4, 197-203.

Culliney, T. W. \& Grace, J. K. (2000). Prospects for the biological control of subterranean termites (Isoptera: rhinotermitidae), with special reference to Coptotermes formosanus. Bull Entomol Res 90, 9-21.

De la Rosa, W., Alatorre, R., Barrera, J. F. \& Toreillo, C. (2000). Effect of Beauveria bassiana and Metarhizium anisopliae (Deuteromycetes) upon the coffee berry borer (Coleoptera: Scolytidae) under field conditions. J Econ Entomol 93, 1409-1414.

El Basyouni, S. H. \& Vining, L. C. (1966). Biosynthesis of oosporein in Beauveria bassiana (Bals.) Vuill. Can J Biochem 44, 557-565.

Farmerie, W., Hammer, J., Liu, L., Sahni, A. \& Scneider, M. (2005). Biological workflow with BlastQuest. Data Knowledge Engineer 53, 75-97.

Ferron, P. (1981). Pest control by the fungi Beauveria and Metarhizium. In Microbial Control of Pests and Plant Diseases 19701980, pp. 465-482. Edited by H. D. Burges. New York: Academic Press.

Freimoser, F. M., Screen, S., Bagga, S., Hu, G. \& St Leger, R. J. (2003a). Expressed sequence tag (EST) analysis of two subspecies of Metarhizium anisopliae reveals a plethora of secreted proteins with potential activity in insect hosts. Microbiology 149, 239-247.

Freimoser, F. M., Screen, S., Hu, G. \& St Leger, R. (2003b). EST analysis of genes expressed by the zygomycete pathogen Conidiobolus coronatus during growth on insect cuticle. Microbiology 149, 1893-1900.

Freimoser, F. M., Hu, G. \& St Leger, R. J. (2005). Variation in gene expression patterns as the insect pathogen Metarhizium anisopliae adapts to different host cuticles or nutrient deprivation in vitro. Microbiology 151, 361-371.

Fujimura-Kamada, K., Nouvet, F. J. \& Michaelis, S. (1997). A novel membrane-associated metalloprotease, Ste24p, is required for the first step of $\mathrm{NH}_{2}$-terminal processing of the yeast a-factor precursor. J Cell Biol 136, 271-285.
Gillespie, J. P., Bailey, A. M., Cobb, B. \& Vilcinskas, A. (2000). Fungi as elicitors of insect immune responses. Arch Insect Biochem Physiol 44, 49-68.

Glinski, M., Urbanke, C., Hornbogen, T. \& Zocher, R. (2002). Enniatin synthetase is a monomer with extended structure: evidence for an intramolecular reaction mechanism. Arch Microbiol 178, 267-273.

Grogan, G. J. \& Holland, H. L. (2000). The biocatalytic reactions of Beauveria spp. J Mol Catal B Enzym 9, 1-32.

Gum, J. R., Jr, Hicks, J. W., Toribara, N. W., Siddiki, B. \& Kim, Y. S. (1994). Molecular cloning of human intestinal mucin (MUC2) cDNA. Identification of the amino terminus and overall sequence similarity to prepro-von Willebrand factor. J Biol Chem 269, 2440-2446.

Gupta, S. C., Leathers, T. D., El-Sayed, G. N. \& Ignoffo, C. M. (1992). Insect cuticle-degrading enzymes from the entomogenous fungus Beauveria bassiana. Exp Mycol 16, 132-137.

Haese, A., Schubert, M., Herrmann, M. \& Zocher, R. (1993). Molecular characterization of the enniatin synthetase gene encoding a multifunctional enzyme catalysing $\mathrm{N}$-methyldepsipeptide formation in Fusarium scirpi. Mol Microbiol 7, 905-914.

Han, E. K., Cotty, F., Sottas, C., Jiang, H. \& Michels, C. A. (1995). Characterization of AGT1 encoding a general $\alpha$-glucoside transporter from Saccharomyces. Mol Microbiol 17, 1093-1107.

Harris, M. A., Clark, J., Ireland, A. \& 56 other authors (2004). The Gene Ontology (GO) database and informatics resource. Nucleic Acids Res 32, D258-D261.

Herrmann, M., Zocher, R. \& Haese, A. (1996). Effect of disruption of the enniatin synthetase gene on the virulence of Fusarium avenaceum. Mol Plant Microbe Interact 9, 226-232.

Inoue, H., Kimura, T., Makabe, O. \& Takahashi, K. (1991). The gene and deduced protein sequences of the zymogen of Aspergillus niger acid proteinase A. J Biol Chem 266, 19484-19489.

Isaka, M., Kittakoop, P., Kirtikara, K., Hywel-Jones, N. L. \& Thebtaranonth, Y. (2005). Bioactive substances from insect pathogenic fungi. Acc Chem Res 38, 813-823.

Jeffs, L. B. \& Khachatourians, G. G. (1997). Toxic properties of Beauveria pigments on erythrocyte membranes. Toxicon 35, 1351-1356.

Kagamizono, T., Nishino, E., Matsumoto \& 8 other authors (1995). Bassiatin, a new platelet aggregation inhibitor produced by Beauveria bassiana K-717. J Antibiot 48, 1407-1412.

Kamyar, M., Rawnduzi, P., Studenik, C. R., Kouri, K. \& LemmensGruber, R. (2004). Investigation of the electrophysiological properties of enniatins. Arch Biochem Biophys 429, 215-223.

Khachatourians, G. G. (1992). Virulence of five Beauveria strains, Paecilomyces farnosus, and Verticillium lecanii against the migratory grasshopper, Melanoplus sanguinipes. J Invertebr Pathol 59, 212-214.

Kirkland, B. H., Westwood, G. S. \& Keyhani, N. O. (2004). Pathogenicity of entomopathogenic fungi Beauveria bassiana and Metarhizium anisopliae to Ixodidae tick species Dermacentor variabilis, Rhipicephalus sanguineus, and Ixodes scapularis. J Med Entomol 41, 705-711.

Kirkland, B. H., Eisa, A. \& Keyhani, N. O. (2005). Oxalic acid as a fungal acaracidal virulence factor. J Med Entomol 42, 346-351.

Kucera, M. \& Samsinakova, A. (1968). Toxins of the entomophagous fungus Beauveria bassiana. J Invertebr Pathol 12, 316-320.

Lawen, A. (1996). Biosynthesis and mechanism of action of cyclosporins. Prog Med Chem 33, 53-97.

Leathers, T. D. \& Gupta, S. C. (1993). Susceptibility of the eastern tent caterpillar (Malacosma americanum) to the entomogenous fungus Beauveria bassiana. J Invertebr Pathol 61, 217-219. 
Leathers, T. D., Gupta, S. C. \& Alexander, N. J. (1993). Mycopesticides: status, challenges, and potential. J Ind Microbiol 12, 69-75.

Lewis, L. C., Bruck, D. J., Gunnarson, R. D. \& Bidne, K. G. (2001). Assessment of plant pathogenicity of endophytic Beauveria bassiana in Bt transgenic and non-transgenic corn. Crop Sci 41, 1395-1400.

McCoy, C. W. (1990). Entomogenous fungi as microbial pesticides. In New Directions in Biological Control, pp. 139-159. Edited by R. R. Baker \& P. E. Dunn. New York: A. R. Liss.

McCreath, K. J., Specht, C. A. \& Robbins, P. W. (1995). Molecular cloning and characterization of chitinase genes from Candida albicans. Proc Natl Acad Sci U S A 92, 2544-2548.

Oda, N., Gotoh, Y., Oyama, H., Murao, S., Oda, K. \& Tsuru, D. (1998). Nucleotide sequence of the gene encoding the precursor protein of pepstatin insensitive acid protease B, scytalidopepsin B, from Scytalidium lignicolum. Biosci Biotechnol Biochem 62, 1637-1639.

Pegram, R. A., Wyatt, R. D. \& Smith, T. L. (1982). Oosporeintoxicosis in the turkey poultry. Avian Dis 26, 47-59.

Pendland, J. C. \& Boucias, D. G. (1998). Characterization of monoclonal antibodies against cell wall epitopes of the insect pathogenic fungus, Nomuraea rileyi: differential binding to fungal surfaces and cross-reactivity with host hemocytes and basement membrane components. Eur J Cell Biol 75, 118-127.

Pendland, J. C., Hung, S. Y. \& Boucias, D. G. (1993). Evasion of host defense by in vivo-produced protoplast-like cells of the insect mycopathogen Beauveria bassiana. J Bacteriol 175, 5962-5969.

Pfeifer, T. A. \& Khachatourians, G. G. (1993). Electrophoretic karyotype of the entomopathogenic deuteromycete Beauveria bassiana. J Invertebr Pathol 61, 231-235.

Regenberg, B., During-Olsen, L., Kielland-Brandt, M. C. \& Holmberg, S. (1999). Substrate specificity and gene expression of the amino-acid permeases in Saccharomyces cerevisiae. Curr Genet 36, 317-328.

Roncero, C. (2002). The genetic complexity of chitin synthesis in fungi. Curr Genet 41, 367-378.

Ruiz-Herrera, J., Gonzalez-Prieto, J. M. \& Ruiz-Medrano, R. (2002). Evolution and phylogenetic relationships of chitin synthases from yeasts and fungi. FEMS Yeast Res 1, 247-256.
Seger, C., Erlebach, D., Stuppner, H., Griesser, U. J. \& Strasser, H. (2005). Physicochemical properties of oosporein, the major secreted metabolite of the entomopathogenic fungus Beauveria brongniartii. Helv Chim Acta 88, 802-810.

Sophianopoulou, V. \& Scazzocchio, C. (1989). The proline transport protein of Aspergillus nidulans is very similar to amino acid transporters of Saccharomyces cerevisiae. Mol Microbiol 3, 705-714.

St Leger, R., Charnley, A. K. \& Cooper, R. M. (1986). Cuticledegrading enzymes from entomopathogenic fungi: synthesis in culture on cuticle. J Invertebr Pathol 48, 85-95.

St Leger, R., Joshi, L., Bidochka, M. J. \& Roberts, D. W. (1996). Construction of an improved mycoinsecticide overexpressing a toxic protease. Proc Natl Acad Sci U S A 93, 6349-6354.

Takahashi, S., Uchida, K., Kakinuma, N., Hashimoto, R., Yanagisawa, T. \& Nakagawa, A. (1998). The structures of pyridovericin and pyridomacrolidin, new metabolites from the entomopathogenic fungus, Beauveria bassiana. J Antibiot 51, 1051-1054.

Vasseur, V., Van Montagu, M. \& Goldman, G. H. (1995). Trichoderma harzianum genes induced during growth on Rhizoctonia solani cell walls. Microbiology 141, 767-774.

Viaud, M., Couteaudier, Y., Levis, C. \& Riba, G. (1996). Genome organization in Beauveria bassiana: electrophoretic karyotype, gene mapping and telomeric fingerprints. Fungal Genet Biol 20, 175-183.

Wang, C. \& St Leger, R. J. (2005). Developmental and transcriptional responses to host and nonhost cuticles by the specific locust pathogen Metarhizium anisopliae var. acridum. Eukaryot Cell 4, 937-947.

Wang, C., Hu, G. \& St Leger, R. J. (2005). Differential gene expression by Metarhizium anisopliae growing in root exudate and host (Manduca sexta) cuticle or hemolymph reveals mechanisms of physiological adaptation. Fungal Genet Biol 42, 704-718.

Wraight, S. P., Carruthers, R. I., Bradley, C. A., Jaronski, S. T., Lacey, L. A., Wood, P. \& Galaini-Wraight, S. (1998). Pathogenicity of the entomopathogenic fungi Paecilomyces spp. and Beauveria bassiana against the silverleaf whitefly, Bemisia argentifolii. J Invertebr Pathol $71,217-226$.

Zimmermann, C. R., Johnson, S. M., Martens, G. W., White, A. G. \& Pappagianis, D. (1996). Cloning and expression of the complement fixation antigen-chitinase of Coccidioides immitis. Infect Immun 64, 4967-4975. 